\title{
Mitochondria Fusion upon SERCA Inhibition Prevents Activation of the NLRP3 Inflammasome in Human Monocytes
}

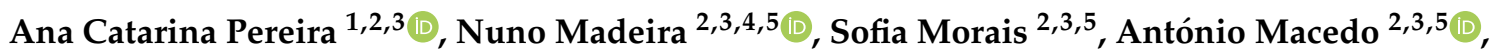 \\ Maria Teresa Cruz ${ }^{1,3,6}$ (D) and Cláudia M. F. Pereira ${ }^{1,2,3, *}$
}

Citation: Pereira, A.C.; Madeira, N.; Morais, S.; Macedo, A.; Cruz, M.T.; Pereira, C.M.F. Mitochondria Fusion upon SERCA Inhibition Prevents Activation of the NLRP3 Inflammasome in Human Monocytes. Cells 2022, 11, 433. https://doi.org/ $10.3390 /$ cells 11030433

Academic Editor: Maurizio Renna

Received: 27 December 2021

Accepted: 25 January 2022

Published: 27 January 2022

Publisher's Note: MDPI stays neutral with regard to jurisdictional claims in published maps and institutional affiliations.

Copyright: (C) 2022 by the authors. Licensee MDPI, Basel, Switzerland. This article is an open access article distributed under the terms and conditions of the Creative Commons Attribution (CC BY) license (https:// creativecommons.org/licenses/by/ $4.0 /)$.
1 CNC - Center for Neuroscience and Cell Biology, CIBB - Center for Innovative Biomedicine and Biotechnology, University of Coimbra, Rua Larga-Faculdade de Medicina, $1^{\circ}$ andar-Polo I Universidade de Coimbra, 3004-504 Coimbra, Portugal; anacatarinajpp@gmail.com (A.C.P.); trosete@ff.uc.pt (M.T.C.)

2 Faculty of Medicine, University of Coimbra, 3000-548 Coimbra, Portugal; nunogmadeira@gmail.com (N.M.); sofiamorais86@gmail.com (S.M.); amacedo@ci.uc.pt (A.M.)

3 CACC - Clinical Academic Center of Coimbra, 3004-561 Coimbra, Portugal

4 CIBIT-Coimbra Institute for Biomedical Imaging and Translational Research, University of Coimbra, Azinhaga de Santa Comba, 3000-548 Coimbra, Portugal

5 Department of Psychiatry, CHUC-UC - Centro Hospitalar e Universitário de Coimbra, 3004-561 Coimbra, Portugal

6 Faculty of Pharmacy, University of Coimbra, 3000-548 Coimbra, Portugal

* Correspondence: cpereira@cnc.uc.pt; Tel.: +351-239-820-190

\begin{abstract}
Sarco/endoplasmic reticulum $\mathrm{Ca}^{2+}$ ATPase (SERCA) is a crucial component of the cellular machinery responsible for $\mathrm{Ca}^{2+}$ homeostasis. The selective inhibition of SERCA by thapsigargin (TG) leads to perturbations in $\mathrm{Ca}^{2+}$ signaling, which can trigger endoplasmic reticulum (ER) stress. The unfolded protein response (UPR) pathway is activated in response to ER stress and induces an adaptive response to preserve cell survival or committee cells to programmed death, depending on stress duration and/or level. Early stages of ER stress stimulate mitochondrial metabolism to preserve survival but under chronic ER stress conditions, mitochondrial dysfunction is induced, which, in turn, can enhance inflammation through NLRP3 inflammasome activation. This study was aimed at investigating the role of SERCA inhibition on NLRP3 inflammasome activation in human monocytes, which was evaluated in primary monocytes isolated from healthy individuals and in the THP-1 human monocytic cell line. Findings obtained in both THP-1 and primary monocytes demonstrate that SERCA inhibition triggered by TG does not activate the NLRP3 inflammasome in these innate immune cells since IL- $1 \beta$ secretion was not affected. Results from THP- 1 monocytes showing that SERCA inhibition increases mitochondrial $\mathrm{Ca}^{2+}$ content and fusion, in the absence of changes in ROS levels and membrane potential, support the view that human monocytes counteract ER stress that arises from inhibition of SERCA through modulation of mitochondrial morphology towards mitochondria fusion, thus preventing NLRP3 inflammasome activation. Overall, this work contributes to a better understanding of the molecular mechanisms that modulate the activity of the NLRP3 inflammasome leading to sterile inflammation, which are still poorly understood.
\end{abstract}

Keywords: calcium homeostasis; endoplasmic reticulum (ER) stress; immune system; sterile inflammation; mitochondria dynamics

\section{Introduction}

Endoplasmic reticulum (ER) is the main intracellular $\mathrm{Ca}^{2+}$ store and the major site for protein synthesis, folding and maturation in eukaryotic cells [1]. The sarco/endoplasmic reticulum $\mathrm{Ca}^{2+}$ ATPase (SERCA) is a pump that belongs to the P-type ATPase family, which uses the energy produced by ATP hydrolysis for the active transport of $\mathrm{Ca}^{2+}$ ions from the cytosol into the sarcoplasmic reticulum or endoplasmic reticulum (ER) lumen, in the case of muscle or non-muscle cells, respectively. Based on its molecular mechanism of action, 
SERCA maintains a low cytosolic $\mathrm{Ca}^{2+}$ concentration playing a pivotal role in the regulation of $\mathrm{Ca}^{2+}$ homeostasis, which is crucial for cell signaling and survival $[2,3]$. Indeed, $\mathrm{Ca}^{2+}$ is a ubiquitous intracellular messenger able to coordinate various cellular functions; however, at high concentrations, $\mathrm{Ca}^{2+}$ becomes cytotoxic [4,5]. Inhibition of SERCA activity has been closely associated with the depletion of $\mathrm{Ca}^{2+}$ levels in ER reservoirs and, subsequently, the disruption of ER functions, namely the activity of the $\mathrm{Ca}^{2+}$-dependent ER chaperons, which leads to the accumulation of unfolded proteins in the ER lumen, triggering ER stress [5-7]. Thapsigargin (TG) is a specific SERCA inhibitor described as a known ER stressor and therefore as an activator of the unfolded protein response (UPR) cascade, which consists of a set of transcriptional and translational events triggered in response to cellular stress [8,9].

Regarding ER stress signaling, BiP/GRP78 chaperone, which is critical for ER protein quality control, is associated with the three ER stress sensors of the UPR: protein kinase Rlike ER kinase (PERK), inositol-requiring enzyme 1 alpha (IRE1 $\alpha$ ), and transcription factor 6 (ATF6), keeping them inactive during resting conditions. Upon ER stress, BiP/GRP78 chaperone binds to unfolded proteins accumulated in the ER lumen, which leads to dissociation of BiP/GRP78 protein from the ER stress sensors, culminating in UPR activation $[10,11]$. Depending on the level of cell stress, UPR orchestrates an adaptive response able to restore ER homeostasis and avoid cell death, or can trigger UPR-mediated apoptosis $[9,12,13]$.

In addition to the UPR, cells also have other signaling mechanisms that act as strategic responses to help them deal with stressful conditions. The ER transmembrane chaperone Sigma-1 receptor (Sigma-1R) seems to be fundamental to trigger and fit anti-stress responses, since it can interact with multiple proteins and exhibit pleotropic effects $[14,15]$. For instance, Sigma-1R interacts with BiP/GRP78 chaperone, forming a complex at MAM surface. Upon ER $\mathrm{Ca}^{2+}$ depletion, which can arise from chronic ER stress, Sigma-1R dissociates from $\mathrm{BiP} / \mathrm{GRP78}$ in order to regulate $\mathrm{Ca}^{2+}$ flux from the ER into mitochondria via IP3 receptors (IP3Rs). In addition, Sigma-1R also influences bioenergetics and cellular survival through modulation of ER Ca ${ }^{2+}$ signaling, [16,17]. Recently, Sigma-1R was found particularly enriched in specialized ER-subdomains, called mitochondria-associated membranes (MAMs), which are contact sites resulting from the physical interaction of ER and mitochondria, thus suggesting its role in regulating ER-mitochondria communication [16].

Chronic/severe ER stress often triggers inflammatory responses, culminating in systemic metabolic dysfunction [18]. Over the last few years, multiprotein complexes called NLRP3 inflammasomes have been identified as central players in innate immune responses [19]. They are composed by a cytosolic pattern-recognition receptor, the Nodlike receptor pyrin domain containing 3 (NLRP3), the enzyme caspase-1, and the adaptor protein termed apoptosis-associated speck-like protein containing a CARD (ASC). The selfassociation of all these components leads to inflammasome activation, which is characterized by caspase-1-dependent maturation of the proinflammatory cytokines interleukin-1 $\beta$ (IL-1 $\beta$ ) and interleukin-18 (IL-18). NLRP3 is the best-characterized inflammasome and has been defined as a driver of inflammation in response to mitochondrial damage. Classic NLRP3 activating stimuli include reactive oxygen species (ROS), release of mitochondrial DNA (mtDNA), cardiolipin externalization, release of cathepsins into the cytosol after lysosomal destabilization, and alterations in $\mathrm{Ca}^{2+}$ homeostasis [20-22]. Mitochondrial dysfunction is intrinsically linked to loss of mitochondrial membrane potential and disrupted mitochondrial network dynamics [23]. In healthy cells, mitochondrial morphology depends on a dynamic equilibrium between fission and fusion events. Mitochondrial fusion is coordinated by mitofusins (MFN1, MFN2), whereas dynamin-related protein 1 (DRP1) is defined as the major mediator of mitochondrial fission [24]. In addition to dynamic regulation of mitochondrial morphology, MFN2 also modulates ER-mitochondria tethering [25]. Induction of stress conditions has been closely associated with a dynamic remodeling of mitochondrial morphology [26,27]. Under acute ER stress conditions, a protective mechanism mediated by enhanced mitochondrial fusion can be stimulated to prevent pathologic mitochondrial fragmentation and promote mitochondrial metabolism, which is dependent on membrane potential [27]. Under severe stress conditions, there is 
an imbalance in the highly conserved dynamic processes towards mitochondrial fission, which is linked to the loss of mitochondrial membrane potential that acts as a signal to facilitate fragmentation and degradation of damaged mitochondria by mitophagy $[26,28]$. Recent studies suggest that perturbations in mitochondrial fission contribute to NLRP3 inflammasome-mediated inflammation $[29,30]$.

This study aimed to investigate whether SERCA inhibition, and subsequent induction of ER stress, activates the NLRP3 inflammasome leading to sterile inflammation in human monocytes. Furthermore, the relationship between mitochondrial dysfunction and NLRP3 inflammasome activation under these conditions was also evaluated in human THP-1 monocytes.

\section{Materials and Methods}

\subsection{Materials}

The THP-1 human monocytic cell line (ATCC TIB-202) was bought from InvivoGen (Toulouse, France). RPMI 1640 medium, penicillin, streptomycin, thapsigargin, bicinchoninic acid (BCA) protein assay kit, and tetramethyl-rhodamine ethyl ester (TMRE) probe were obtained from Sigma Chemical Co. (St. Louis, MO, USA). Fetal bovine serum (FBS) was from Gibco, Life Technologies (Paisley, UK). The fluorescent probes MitoSOX red mitochondrial superoxide indicator, Hoechst 33342, and Rhodamine-2 acetoxymethyl ester (Rhod-2 AM) were obtained from Invitrogen (Eugene, OR, USA). Carbonyl cyanide p-trifluoromethoxyphenylhydrazone (FCCP) and the selective inhibitor RU 360 were obtained from Merck (Kenilworth, NJ, USA). All reagents used for culture primary monocytes including RPMI 1640 medium HEPES no glutamine, penicillin, streptomycin, sodium pyruvate, glutamax, non-essential amino acids, and heat-inactivated fetal bovine serum (FBS) were obtained from Gibco, Thermo Fisher Scientific (Waltham, MA, USA). Human monocytes isolation kit II was obtained from Miltenyi Biotec (Gladbach, Germany). Legend MAX Human IL-1 $\beta$ ELISA kit with precoated plates was obtained from Biolegend (San Diego, CA, USA). Protease- and phosphatase-inhibitor cocktails were obtained from Roche (Mannheim, Germany), and the NZY colour protein marker II was from NZYTech (Lisbon, Portugal). The alkaline phosphatase-linked secondary antibodies and the enhanced chemifluorescence (ECF) reagent were obtained from GE Healthcare (Chalfont St. Giles, $\mathrm{UK}$ ), and the polyvinylidene difluoride membranes were from Millipore Corporation (Bedford, MA, USA). Antibodies against ATF4, CHOP, and Sigma-1R were from Cell Signaling Technology (Danvers, MA, USA). The anti-XBP1s and anti-DRP1 (Ser616) antibodies were from Biolegend (San Diego, CA, USA). Anti-Mitofusin 2 antibody was from Santa Cruz Biotechnology (Dallas, TX, USA), and anti-GRP78 was from BD Biosciences (San Jose, CA, USA). All other reagents were from Sigma Chemical Co. (St. Louis, MO, USA).

\subsection{Methods}

\subsubsection{THP-1 Cell Culture}

The THP-1 human monocytic cell line was cultured and maintained in $75 \mathrm{~cm}^{2}$ flasks at a cell density between $0.5-1.0 \times 10^{6}$ cells $/ \mathrm{mL}$ in RPMI 1640 medium supplemented with $10 \%(v / v)$ heat-inactivated fetal bovine serum (FBS), $25 \mathrm{mM}$ glucose, $10 \mathrm{mM}$ Hepes, $1 \mathrm{mM}$ sodium pyruvate, $100 \mathrm{U} / \mathrm{mL}$ penicillin, and $100 \mu \mathrm{g} / \mathrm{mL}$ streptomycin. Cells were maintained at $37^{\circ} \mathrm{C}$ in a humidified incubator under an atmosphere containing $5 \% \mathrm{CO}_{2}$. Cells were sub-cultured every 2-3 days and kept in culture for a maximum of 2 months.

\subsubsection{Isolation and Culture of Primary Human Monocytes}

Peripheral blood $(\sim 20 \mathrm{~mL})$ was collected by vein puncture from healthy male subjects, aged between 18 and 35 years old, upon written informed consent and study approval by the Ethical Committee of the Coimbra University Hospital (150/CES, 3 July).

Collected peripheral blood was diluted $2 \times$ by addition of sterile phosphate-buffered saline (PBS), pH 7.4, and then $20 \mathrm{~mL}$ of diluted blood was carefully added to $12 \mathrm{~mL}$ of ficoll-paque plus. After centrifugation at $1100 \times g$ for $20 \mathrm{~min}$ at room temperature (RT), with 
the centrifuge brake turned off, the mononuclear fraction was collected and subsequently diluted in $50 \mathrm{~mL}$ sterile PBS. A subsequent centrifugation at $300 \times g$ for $10 \mathrm{~min}$ at RT was used to pellet cells that were resuspended in $50 \mathrm{~mL}$ sterile PBS, and then they were centrifuged again at $200 \times g$ for $10 \mathrm{~min}$ at RT in order to remove platelets. Peripheral blood mononuclear cells (PBMCs) were then resuspended in $10 \mathrm{~mL}$ sterile PBS, and the number of cells were determined using an Eve Automatic Cell Counter (NanoEnTeK, Waltham, MA, USA).

Upon resuspension in MACS buffer (PBS, pH 7.2, supplemented with $0.5 \%(v / v)$ FBS and $2 \mathrm{mM}$ EDTA), monocytes were then isolated by using a human monocyte isolation kit II according to the manufacturer's instructions. Briefly, the mononuclear fraction was incubated with CD14 microbeads during $15 \mathrm{~min}$ at $4{ }^{\circ} \mathrm{C}$. Pelleted cells were resuspended in MACS buffer and then centrifuged at $300 \times g$ for $10 \mathrm{~min}$ at RT. After resuspension again in MACS buffer, cell suspension was loaded onto a LS magnetic column placed in the magnetic field of a MACS separator and rinsed three times with the same buffer. Finally, the $\mathrm{CD} 14^{+}$fraction was eluted in MACS buffer, centrifuged at $300 \times g$ for $10 \mathrm{~min}$ at RT, and then cultured at a density of $0.8 \times 10^{6}$ cells $/ \mathrm{mL}$ in glutamine-free RPMI 1640 Medium, supplemented with HEPES, $10 \%(v / v)$ heat-inactivated FBS, $100 \mathrm{U} / \mathrm{mL}$ penicillin, $100 \mu \mathrm{g} / \mathrm{mL}$ streptomycin, $2 \mathrm{mM}$ glutamax, $1 \mathrm{mM}$ sodium pyruvate, and $0.1 \mathrm{mM}$ non-essentials amino acids. Cells were maintained at $37^{\circ} \mathrm{C}$ in a humidified incubator under an atmosphere containing $5 \% \mathrm{CO}_{2}$.

\subsubsection{Total Cell Lysates Preparation}

THP-1 monocytes were plated in a 6-well plate at a density of $2.4 \times 10^{6}$ cells/well and treated in the absence or presence of 5 or $10 \mu \mathrm{M}$ thapsigargin (TG) for the indicated time periods (1-24 h). After incubation, cells were washed with cold PBS, pH 7.4, and lysed on ice with ice-cold lysis RIPA buffer ( $50 \mathrm{mM}$ Tris- $\mathrm{HCl}(\mathrm{pH} 8.0), 1 \%(v / v)$ Nonidet P-40, $150 \mathrm{mM} \mathrm{NaCl}, 0.5 \%(w / v)$ sodium deoxycholate, $0.1 \%(w / v)$ SDS, $2 \mathrm{mM}$ EDTA, and $1 \mathrm{mM}$ DTT) freshly supplemented with a protease and phosphatase inhibitor cocktail. Nuclei and insoluble cell debris were removed by centrifugation at $12,000 \times \mathrm{g}$ for $10 \mathrm{~min}$ at $4{ }^{\circ} \mathrm{C}$, and the supernatant was collected and stored at $-80^{\circ} \mathrm{C}$ until further use.

The total protein amount was determined using the bicinchoninic acid (BCA) method. Then, proteins on cell lysates were denatured in sample buffer $(5 \%(w / v)$ SDS, $0.125 \mathrm{M}$ Tris-HCl pH 6.8, 20\% (v/v) glycerol, 10\% (v/v) 2-mercaptoethanol and bromophenol blue) by heating for $5 \mathrm{~min}$ at $95^{\circ} \mathrm{C}$.

\subsubsection{Western Blotting}

Briefly, proteins $(40 \mu \mathrm{g})$ were separated by electrophoresis on $10 \%(v / v)$ sodium dodecyl sulphate-polyacrylamide gels (SDS-PAGE) at $130 \mathrm{~V}$ for 60-75 $\mathrm{min}$ and then transferred to a methanol-activated polyvinylidene difluoride (PVDF) membrane by electroblotting using a Trans-Blot Cell wet transfer system (Bio-Rad, Hercules, CA, USA) at $400 \mathrm{~mA}$ for $3 \mathrm{~h}$ at $4{ }^{\circ} \mathrm{C}$. After blocking with $5 \%(w / v)$ nonfat dry milk in Tris-buffered saline ((TBS): $150 \mathrm{mM}$ $\mathrm{NaCl}, 25 \mathrm{mM}$ Tris-HCl pH 7.6) containing 0.1\% $(v / v)$ Tween 20 (TBS-T) for $1 \mathrm{~h}$, at RT, membranes were incubated with the primary antibodies diluted in TBS-T with $1 \%(w / v)$ nonfat dry milk overnight at $4{ }^{\circ} \mathrm{C}$. After washing with TBS-T, membranes were incubated for $1 \mathrm{~h}$ at RT with alkaline phosphatase-conjugated anti-rabbit or anti-mouse $(1: 20,000)$ antibodies. After an additional washing step with TBS-T, the immune complexes were detected with the enhanced chemifluorescence (ECF) reagent using the scanning system Typhoon FLA 9000 (GE Healthcare, Chalfont St. Giles, UK). Total Lab TL 120 software (GE Healthcare, Chicago, IL, USA) was used to quantify the optical density of the bands. The results obtained were normalized to $\beta$-tubulin I protein loading control. At the end, results were normalized to control (untreated cells). 


\subsubsection{Determination of Secreted IL-1 $\beta$ Levels in the Cell Supernatant}

THP-1 human monocytic cell line was plated in 12-well plates at a density of $1.2 \times 10^{6}$ cells/ well and then treated with LPS for $24 \mathrm{~h}$, prior to treatment with 5 or $10 \mu \mathrm{M}$ TG for $8 \mathrm{~h}$. As a positive control, THP- 1 cells were exposed to $1 \mu \mathrm{g} / \mathrm{mL}$ LPS for $24 \mathrm{~h}$ plus $5 \mathrm{mM}$ ATP for $30 \mathrm{~min}$. Human primary monocytes were plated in a 96-well plate at a density of $0.12 \times 10^{6}$ cells/well and then treated with $10 \mu \mathrm{M}$ TG for $8 \mathrm{~h}$ in the presence or absence of LPS pre-incubated during $24 \mathrm{~h}$. Briefly, untreated and treated cells were centrifuged at $400 \times g$ for $5 \mathrm{~min}$, and the supernatants were collected and stored at $-80^{\circ} \mathrm{C}$ for subsequent use. IL-1 $\beta$ secretion in THP-1 monocytes and in primary human monocytes was measured with an ELISA kit according to the manufacturer's instructions. Absorbance values were measured in a standard Synergy HT Multi Detection Microplate Reader (BioTek Instruments, Winooski, VT, USA) set to $450 \mathrm{~nm}$ and $570 \mathrm{~nm}$ wavelengths. IL- $1 \beta$ secreted levels were expressed as $\mathrm{pg} / \mathrm{mL}$.

\subsubsection{Determination of Mitochondrial Membrane Potential Assay}

The fluorescent probe tetramethylrhodamine ethyl ester (TMRE) was used to detect alterations in mitochondrial membrane potential induced by TG in monocytes. For that, THP-1 cells were plated in a 48-well plate at a density of $0.3 \times 10^{6}$ cells/well and then treated with 5 or $10 \mu \mathrm{M}$ TG for 4 or $8 \mathrm{~h}$. Cells treated with $50 \mu \mathrm{M}$ carbonyl cyanide ptrifluoromethoxyphenylhydrazone (FCCP) for $10 \mathrm{~min}$ were used as a positive control for loss of mitochondrial membrane potential. After incubation for $30 \mathrm{~min}$ at $37^{\circ} \mathrm{C}$ with $1 \mu \mathrm{M}$ TMRE in PBS containing 0.2\% $(w / v)$ BSA, control and TG-treated cells were resuspended in PBS containing $0.2 \%(w / v)$ BSA, and the fluorescence was monitored with a Synergy HT Multi Detection Microplate Reader (BioTek Instruments, Winooski, VT, USA) set to $549 \mathrm{~nm}$ excitation and $575 \mathrm{~nm}$ emission wavelengths. Results were normalized to cells in the absence of TG exposure.

\subsubsection{Detection of Mitochondrial ROS Production}

The fluorescent MitoSOX probe was used to evaluate the mitochondrial production of superoxide in control and TG-treated monocytes. For that, human THP-1 cells were plated in 12-well plates at a density of $1.2 \times 10^{6}$ cells/well and then incubated in the absence or presence of 5 or $10 \mu \mathrm{M}$ TG for 4 or $8 \mathrm{~h}$. Cells were washed with PBS and subsequently incubated in Hanks' Balanced Salt Solution (HBSS) containing $5 \mu \mathrm{M}$ MitoSOX and $0.5 \mu \mathrm{g} / \mathrm{mL}$ Hoechst 33342 for $10 \mathrm{~min}$ at $37^{\circ} \mathrm{C}$. Once washed again with PBS, cells were resuspended in HBSS free of supplements. Finally, the fluorescent signal was monitored using an Observer Z.1 fluorescence microscope (Zeiss, Oberkochen, Germany). Images were captured using the Apochromat $63 \times / 1.40$ Oil DIC M27 objective. The results were normalized to cells in the absence of TG exposure.

\subsubsection{Transmission Electron Microscopy (TEM)}

Electron microscopy was used to evaluate mitochondria morphological alterations in TG-treated human THP-1 monocytes. For this purpose, cells were plated in 6-well plates at a density of $2.4 \times 10^{6}$ cells / well in a final volume of $3 \mathrm{~mL}$ and were then treated with $10 \mu \mathrm{M}$ TG for $8 \mathrm{~h}$. Briefly, cells were collected and centrifuged at $1008 \times g$ for $5 \mathrm{~min}$. The supernatant was discarded, and pelleted cells were fixed with $2.5 \%(w / v)$ glutaraldehyde in $0.1 \mathrm{M}$ sodium cacodylate buffer ( $\mathrm{pH} 7.2$ ) for $2 \mathrm{~h}$. Cells were rinsed in the same buffer, and post-fixation was performed using $1 \%(w / v)$ osmium tetroxide for $1 \mathrm{~h}$. After rinsing with buffer, samples were dehydrated in a graded ethanol series (70-100\%). Following embedding in $2 \%(w / v)$ molten agar, samples were re-dehydrated in ethanol (30-100\%), impregnated, and included in Epoxy resin (Fluka Analytical, Munich, Germany). Ultrathin sections were mounted on copper grids, and observations were carried out at $100 \mathrm{kV}$ on Tecnai $\mathrm{G}^{2}$ Spirit BioTwin electron microscope (FEI, Hillsboro, OR, USA). 


\subsubsection{Detection of Mitochondrial Calcium Content}

The rhodamine-2 acetoxymethyl ester (Rhod-2/AM) fluorescent probe was used to determine the mitochondrial calcium content in controls and in monocytes upon TG treatment. For that purpose, human THP-1 cells were cultured in 12-well plates at a density of $1.2 \times 10^{6}$ cells/well and treated in the absence or in the presence of 5 or $10 \mu \mathrm{M}$ TG for 4 or $8 \mathrm{~h}$. Cells treated with the selective inhibitor of mitochondrial calcium uniporter (MCU), RU 360 (10 $\mu \mathrm{M}, 1 \mathrm{~h})$, were used as a positive control to Rhod-2 localization in the mitochondria.

After washing with PBS, cells were resuspended in HBSS containing $10 \mu \mathrm{M}$ Rhod$2 \mathrm{AM}$ and subsequently incubated for $45 \mathrm{~min}$ at $37{ }^{\circ} \mathrm{C}$. Once washed again with PBS, cells were resuspended in HBSS free of supplements, and the fluorescence values were monitored with a standard spectrophotometer Synergy HT Multi Detection Microplate Reader (BioTek Instruments, Winooski, VT, USA) set to $552 \mathrm{~nm}$ excitation and $581 \mathrm{~nm}$ emission wavelengths. The results were normalized to cells in the absence of TG exposure.

\subsubsection{Evaluation of Cell Viability}

Susceptibility towards TG-induced ER stress was evaluated in human monocytes by the resazurin assay. THP-1 cells were cultured in a 96-well plate at a density of $0.2 \times 10^{6}$ cells/well and treated in the presence or absence of 5 or $10 \mu \mathrm{M}$ TG for $24 \mathrm{~h}$. Cells were incubated with resazurin solution $(50 \mu \mathrm{M}) 4 \mathrm{~h}$ before the end of treatment, at $37^{\circ} \mathrm{C}$. Absorbance values were measured at 570 and $600 \mathrm{~nm}$ in a Synergy HT Multi Detection Microplate Reader (BioTek Instruments, Winooski, VT, USA), and the final values were obtained from the subtraction of results determined at $600 \mathrm{~nm}$ from those measured at $570 \mathrm{~nm}$. Cell viability was determined as percentage (\%) of controls in the absence of TG.

\subsubsection{Statistical Analysis}

Results are presented as mean \pm standard error of the mean (SEM). Comparisons between two groups were made using Student's unpaired $t$ test with one-tailed $p$ value. Oneway ANOVA with unpaired Dunnett's post hoc test was used for multiple comparisons. In both cases, a value of $p<0.05$ was considered statistically significant. Statistical analysis was performed with Prism 7.0 (GraphPad Software, San Diego, CA, USA).

\section{Results}

\subsection{SERCA Inhibition Induces ER Stress in Human Monocytes}

First, induction of ER stress was evaluated in human monocytes treated with TG, a classic SERCA inhibitor. For that, activation of the ER stress-induced UPR signaling pathway was assessed in THP-1 cells treated with 5 or $10 \mu \mathrm{M}$ TG in a time-dependent manner (1-24 h) by measuring the protein levels of UPR markers namely ATF4, XBP1s, GRP78, and CHOP. ATF4 protein levels were found significantly increased at all time points in TG-treated THP-1 monocytes when compared with controls cells (Figure 1A). A time-dependent increase in XBP1s levels was observed in TG-treated cells, which reached statistical significance at $24 \mathrm{~h}$ (Figure 1B). The levels of CHOP and GRP78 showed a tendency to increase, namely at 8 and $24 \mathrm{~h}$ of TG exposure, respectively, although it was not statistically significant (Figure 1C,D). The results showed that SERCA inhibition triggered by TG induces ER stress in human monocytes, as demonstrated by the activation of the UPR pathway. 
A
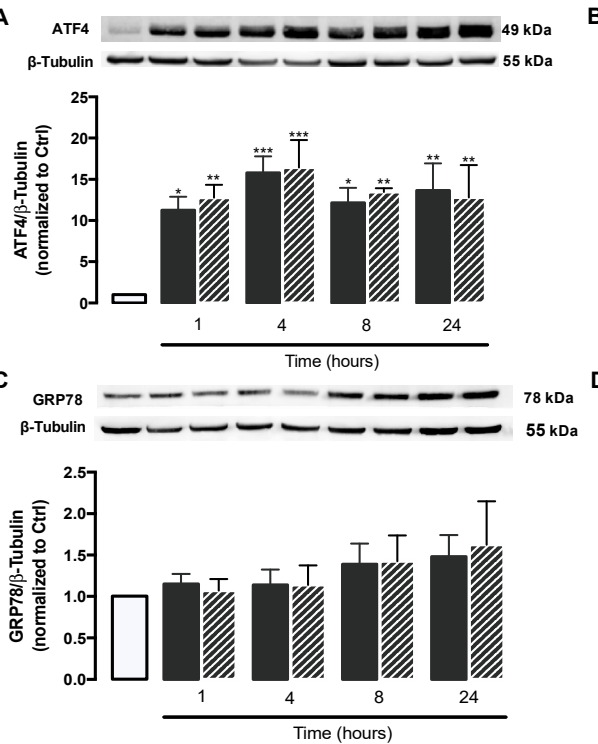

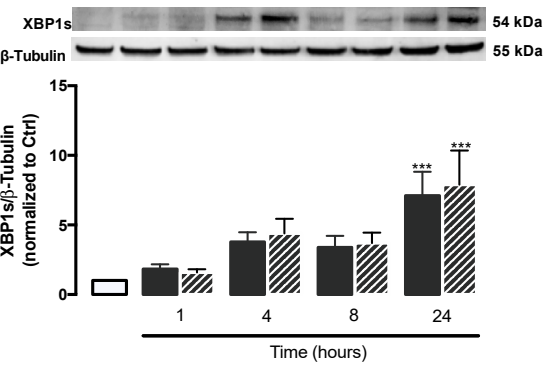

CHoP

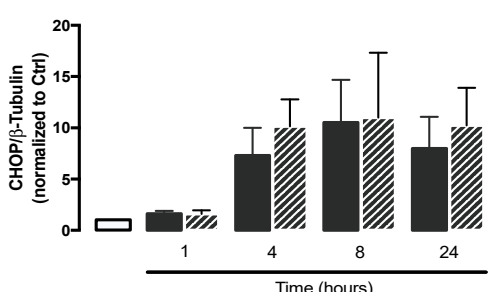

Figure 1. ER stress-induced UPR upon SERCA inhibition in TG-treated human THP-1 monocytes. Protein levels of ER stress markers, namely ATF4 (A), XBP1s (B), GRP78 (C), and CHOP (D), were quantified by WB in total cellular extracts obtained from human THP-1 monocytes treated with 5 or $10 \mu \mathrm{M}$ thapsigargin (TG) during the indicated time periods (1-24 h). $\beta$-Tubulin I was used to control protein loading and to normalize the levels of the protein of interest. Results were calculated relatively to control values and represent the means \pm SEM of at least three independent experiments. Statistical significance between control (untreated cells) and TG-treated cells was determined using the one-way ANOVA test, followed by Dunnett's post hoc test: ${ }^{*} p<0.05 ;{ }^{* *} p<0.01$; ${ }^{* * *} p<0.001$.

\subsection{SERCA Inhibition Is Not Able to Upregulate ER Stress Response Strategies}

Given that Sigma-1R plays a key role in cellular stress signaling, namely under ER stress conditions, its protein levels were evaluated by WB in THP-1 monocytes treated with 5 or $10 \mu \mathrm{M}$ TG in a time-dependent manner (1-24 h). No differences were observed in Sigma-1R levels between controls and TG-treated cells, indicating that ER stress induced by SERCA inhibition does not upregulate Sigma-1R in order to mitigate ER stress (Figure 2).

\subsection{SERCA Inhibition Fails to Promote IL-1 $\beta$ Secretion in Human Monocytes}

Afterwards, the role of SERCA inhibition on NLRP3 inflammasome activation was investigated by measuring the levels of IL- $1 \beta$ secreted by control and TG-treated THP-1 monocytes. In cells treated with LPS, the secretion of IL-1 $\beta$ increased by about 400 -fold in comparison with control cells. The canonical NLRP3 activators LPS plus ATP augmented IL-1 $\beta$ secretion by about 200-fold in comparison with LPS-treated monocytes (Figure 3). No increment in IL-1 $\beta$ levels was detected in supernatants from THP-1 cells treated with LPS plus vehicle or treated with LPS plus TG, suggesting that TG is not able to activate the NLRP3 inflammasome that promotes IL-1 $\beta$ release to the extracellular space.

After demonstrating that TG-induced SERCA inhibition is not able to activate NLRP3 inflammasome in the THP-1 cell line of human monocytes, its effect was also investigated in primary monocytes isolated from peripheral blood (Figure 4). Differences were not observed when comparing the IL- $1 \beta$ levels secreted by control and TG-treated primary monocytes (Figure 4A). Given that NLRP3 inflammasome activation is classically described as a two-signal model, its activity was further assessed in LPS-primed cells. Once again, the secreted levels of IL-1 $\beta$ were similar between monocytes incubated with LPS alone or with LPS plus $10 \mu \mathrm{M}$ TG (Figure 4B). 


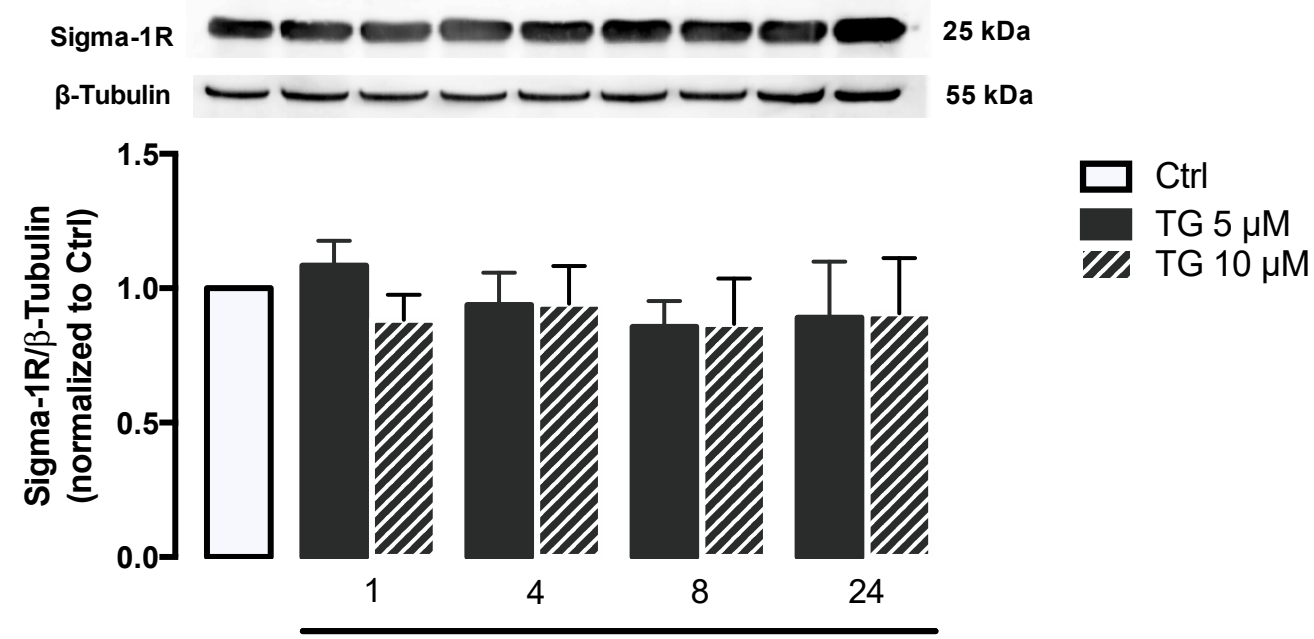

Time (hours)

Figure 2. Stress response under stress conditions triggered by TG-induced SERCA inhibition in human THP-1 monocytes. Protein levels of Sigma-1R were quantified by WB in total cellular extracts obtained after treatment of THP-1 cells with 5 or $10 \mu \mathrm{M}$ thapsigargin (TG) during the indicated time periods (1-24 h). $\beta$-Tubulin I was used as a control for protein loading and to normalize the levels of the protein of interest. Results were calculated relatively to control values and represent the means \pm SEM of at least three independent experiments. Statistical significance between control and TG-treated cells was determined using the one-way ANOVA test, followed by Dunnett's post hoc test.

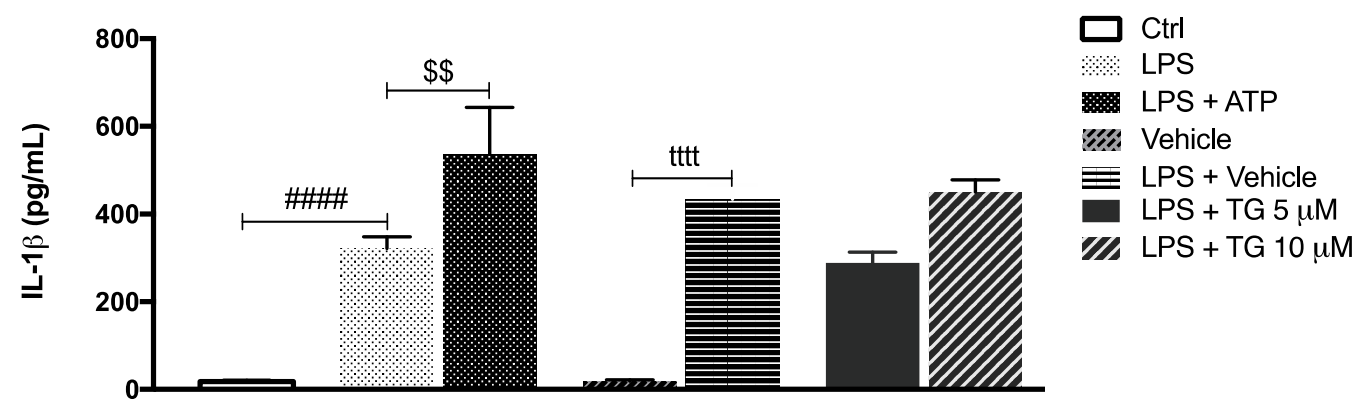

Figure 3. IL-1 $\beta$ secretion upon TG-mediated SERCA inhibition in THP-1 monocytes. Levels of secreted IL-1 $\beta$ were quantified by an ELISA assay in supernatants of THP-1 cells treated with $1 \mu \mathrm{g} / \mathrm{mL}$ LPS alone $(24 \mathrm{~h})$, with LPS $(24 \mathrm{~h})$, and then with 5 or $10 \mu \mathrm{M}$ TG for the last $8 \mathrm{~h}$. Cells primed with $1 \mu \mathrm{g} / \mathrm{mL}$ LPS for $24 \mathrm{~h}$ and then exposed to $5 \mu \mathrm{M}$ ATP for $30 \mathrm{~min}$ were used as a positive control for NLRP3 activation. Results were expressed by $\mathrm{pg} / \mathrm{mL}$ and represent the means $\pm \mathrm{SEM}$ of at least three independent experiments. Statistical significance between LPS and control conditions (Ctrl), LPS and LPS plus ATP, and vehicle and vehicle plus LPS was determined by Student's $t$-test (\#\#\# $p<0.0001, \$$ \$ $p<0.01,{ }^{\text {tttt }} p<0.0001$ ); and between vehicle plus LPS and LPS plus TG-treated cells was determined using the one-way ANOVA test, followed by Dunnett's post hoc test.

These findings indicate that TG-induced SERCA inhibition does not work as an activator of the NLRP3 inflammasome in primary monocytes as well, supporting that this effect is specific of this type of cell from the innate immune system. 
A

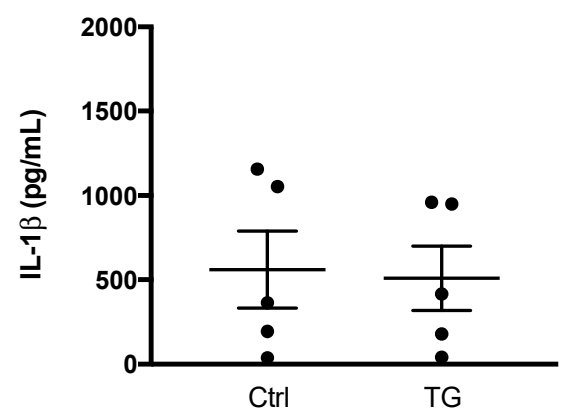

B

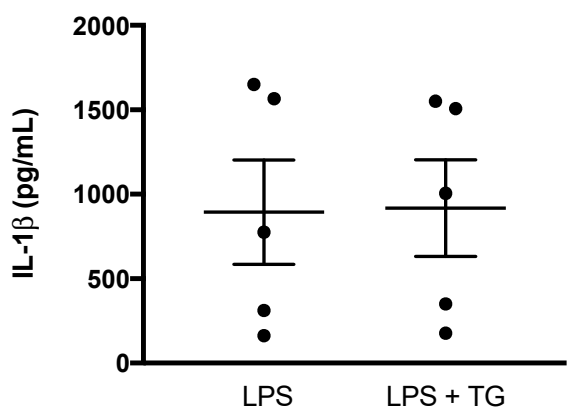

Figure 4. NLRP3 inflammasome activation in primary human monocytes. An ELISA kit was used to quantify the levels of IL-1 $\beta$ in supernatants of untreated (Ctrl) and TG-treated primary human monocytes during $8 \mathrm{~h}(\mathbf{A})$ and in supernatants of monocytes treated with $1 \mu \mathrm{g} / \mathrm{mL}$ LPS alone $(24 \mathrm{~h})$, or with LPS $(24 \mathrm{~h})$ and then with $10 \mu \mathrm{M}$ TG for the last $8 \mathrm{~h}$ (B). Results represent the means \pm SEM results obtained in samples from 5 participants. Statistical significance was determined by Student's $t$-test.

\subsection{NLRP3 Inflammasome-Associated Triggers Are Not Promoted by SERCA Inhibition}

Once it was demonstrated that SERCA inhibition does not activate the NLRP3 inflammasome in human monocytes, some key mitochondrial events that have been described as triggers of inflammasome activation were evaluated, including ROS production, membrane depolarization, and fission. The alterations induced by TG on mitochondrial membrane potential were assessed with the TMRE fluorescent probe using FCCP as a positive control (Figure 5A). In cells treated with this uncoupler of the electron transport chain FCCP, TMRE fluorescence was approximately $50 \%$ of that displayed by control cells. On the other hand, no differences were observed in TMRE fluorescence between control and TG-treated cells at 4 and $8 \mathrm{~h}$, suggesting that SERCA does not induce loss of mitochondrial membrane potential in THP-1 monocytes.

The mitochondrial ROS production in human monocytes was assessed through the MitoSOX probe (Figure 5B). Both control and TG-treated THP-1 cells exhibited similar levels of MitoSOX fluorescence, showing that SERCA inhibition induced by TG does not stimulate the accumulation of oxidant species within mitochondria.

Given that DRP1-mediated mitochondrial fission can trigger NLRP3 inflammasome activation, the levels of DPR1 phosphorylated at Ser616 were evaluated by WB in the absence or presence of SERCA inhibition in human monocytes. No relevant differences were observed in p-DPR1 levels between control and TG-treated THP-1 cells from 1-24 h of TG exposure (Figure 5C).

Taken together, these findings suggest that molecular triggers of NLRP3 inflammasome activation, such as mitochondrial ROS, mitochondrial membrane loss, and fission are not affected by SERCA inhibition in human monocytes.

\subsection{SERCA Inhibition Increases Mitochondrial Fusion and $\mathrm{Ca}^{2+}$ Content}

Then, the effect of SERCA inhibition on mitochondrial fusion was analyzed in human THP-1 monocytes. For that purpose, protein levels of Mitofusin 2, a protein mediator of mitochondria fusion were assessed by WB in controls and in TG-treated cells (Figure 6A). A significant upregulation of Mitofusin 2 was detected upon 8 and $24 \mathrm{~h}$ of exposure to TG when compared to control conditions, suggesting that TG promotes mitochondrial fusion. These findings were further supported by results obtained by TEM, showing that the presence of fused mitochondria is increased in monocytes treated with $10 \mu \mathrm{M}$ TG when compared to untreated cells (Figure 6B). 


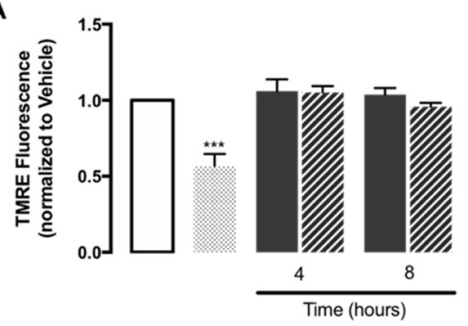

C
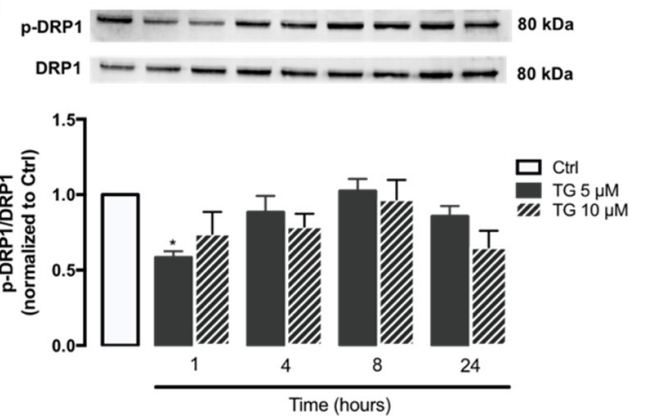
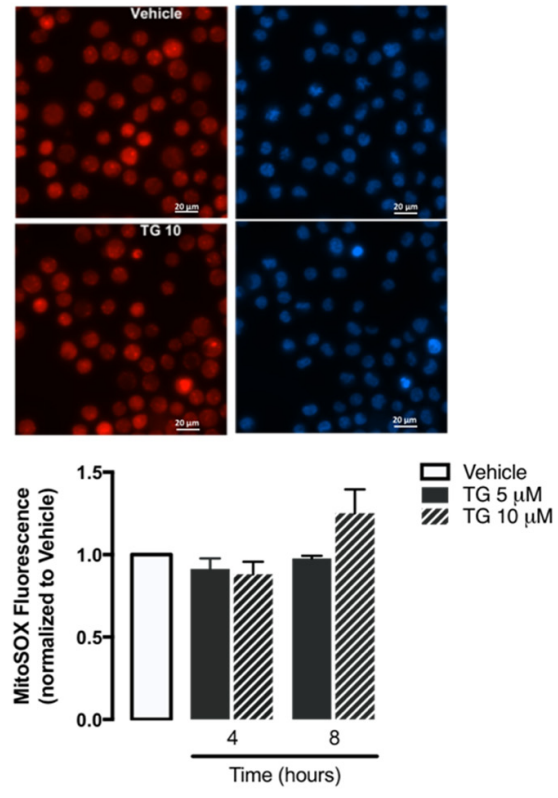

Figure 5. Mitochondrial membrane potential, ROS accumulation, and fission upon TG-induced SERCA inhibition in human THP-1 monocytes. Alterations in mitochondrial membrane potential (A) and mitochondrial ROS retention (B) were measured in THP-1 monocytes treated with 5 or $10 \mu \mathrm{M}$ TG for 4 or 8 , using the TMRE and MitoSOX fluorescent probes, respectively. FCCP was used as a positive experimental control for membrane depolarization. Results were calculated relatively to vehicle values and represent the means \pm SEM of three independent experiments. Statistical significance between vehicle and TG-treated cells was determined using one-way ANOVA test, followed by Dunnett's post hoc test: ${ }^{* * *} p<0.001$. p-DRP1 (Ser616) protein levels (C) were quantified by WB in total cellular extracts obtained after incubation of THP- 1 cells with 5 or $10 \mu \mathrm{M}$ TG during the indicated time periods (1-24 h). Total DRP1 was used to normalize p-DRP1 levels. Results were calculated relatively to control values and represent the means \pm SEM of three independent experiments. Statistical significance between control and TG-treated cells was determined using the one-way ANOVA test, followed by Dunnett's post hoc test: ${ }^{*} p<0.05$.

A
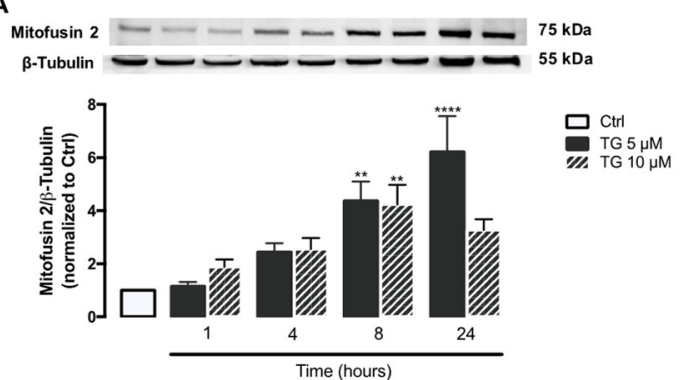

C

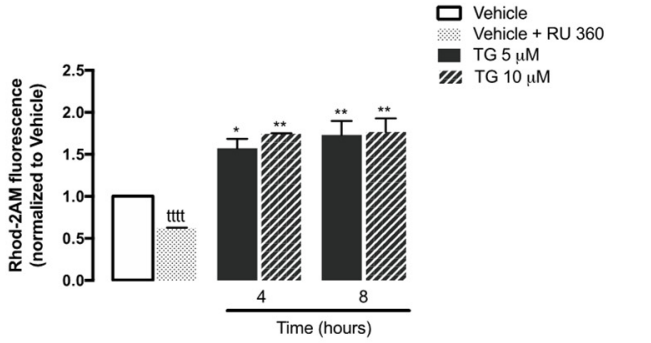

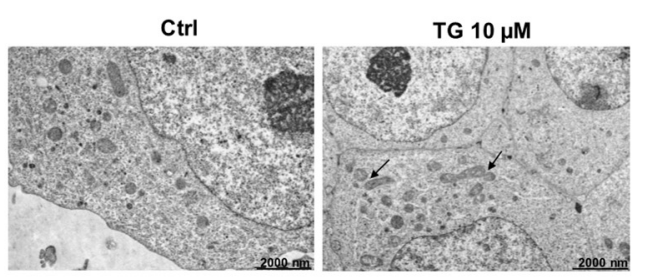

D

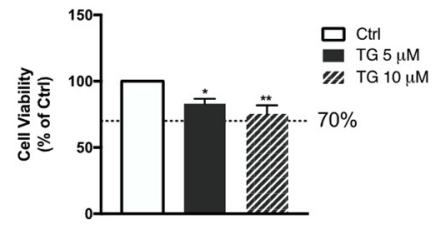

Figure 6. Mitochondrial fusion and $\mathrm{Ca}^{2+}$ content, and susceptibility towards ER stress under TG-induced SERCA inhibition in human THP-1 monocytes. Mfn2 protein levels (A) were quantified by WB in total 
cellular extracts obtained after incubation of THP-1 cells with 5 or $10 \mu \mathrm{M}$ TG during the indicated time periods (1-24 h). $\beta$-Tubulin I was used as a control for protein loading and to normalize the levels of the protein of interest. Results were calculated relatively to control values and represent the means \pm SEM of at least three independent experiments. (B) Representative TEM images of the mitochondrial morphology in TG-treated and untreated THP-1 monocytes. Arrows indicate fused mitochondria. ER-mitochondria $\mathrm{Ca}^{2+}$ transfer (C) in THP-1 cells treated with 5 or $10 \mu \mathrm{M}$ TG for 4 or $8 \mathrm{~h}$ was detected with the fluorescent probe Rhod-2/AM. The selective inhibitor of MCU (RU 360, $10 \mu \mathrm{M}$ ) was used as a positive control for selective mitochondrial Rhod-2 uptake in THP-1 monocytes. Results were calculated relatively to vehicle values and represent the means \pm SEM of at least three independent experiments. Susceptibility of THP- 1 cells to 5 or $10 \mu \mathrm{M}$ TG for $24 \mathrm{~h}$ was assessed by the resazurin assay (D). Results represent the mean \pm SEM of at least three independent experiments and were calculated relatively to control values (untreated cells). Statistical significance between control or vehicle and TG-treated cells was determined using the one-way ANOVA test, followed by Dunnett's post hoc test: ${ }^{*} p<0.05,{ }^{* *} p<0.01,{ }^{* * * *} p<0.0001$. Student's $t$-test was used to compare the statistical significance between vehicle and vehicle plus RU 360-treated cells ( ${ }^{\mathrm{tttt}} p<0.0001$ ).

Mitochondrial $\mathrm{Ca}^{2+}$ content was also evaluated under SERCA inhibition conditions in human monocytes, using the Rhod-2AM fluorescent probe (Figure 6C). When compared with control cells, a significant augment in Rhod-2AM fluorescence was found in THP1 monocytes treated with TG, particularly after 4 and $8 \mathrm{~h}$ incubation, suggesting that SERCA inhibition in these innate immune cells is followed by a rise in mitochondrial $\mathrm{Ca}^{2+}$ content. Moreover, control monocytes were incubated with the selective inhibitor of the MCU, RU 360, in order to ensure that Rhod-2 fluorescence is specifically associated with mitochondria $\mathrm{Ca}^{2+}$ and is not result of probe mislocalization. A significant reduction in Rhod-2 fluorescence was observed in cells treated with RU 360 in comparison with untreated cells, demonstrating that mitochondria $\mathrm{Ca}^{2+}$ is the main source of the observed Rhod-2 fluorescence.

Finally, susceptibility of human monocytes towards SERCA inhibition was assessed by the resazurin assay in cells treated with 5 or $10 \mu \mathrm{M}$ TG for $24 \mathrm{~h}$. Both TG concentrations were shown to decrease cell viability by approximately $20 \%$ (Figure 6D).

\section{Discussion}

Activation of the NLRP3 inflammasome has been implicated in a wide range of diseases. However, the underlying mechanisms remain largely uncertain [31,32]. In order to clarify the signaling pathways that regulate the NLRP3 inflammasome in human monocytes, the role of SERCA inhibition induced by exposure to TG was evaluated in these cells from the innate immune system. For that purpose, both human THP-1 monocytic cell line and primary monocytes were used. The low yield of monocytes isolated from peripheral blood strongly impacted the number of parameters analyzed on these cells. To overcome this limitation, THP-1 human monocytes were used as an in vitro model, allowing us to further explore NLRP3 inflammasome activation.

First, it was demonstrated that inhibition of SERCA activates the ER stress-induced UPR in THP-1 monocytes. More specifically, TG activated both the PERK and IRE1 $\alpha$ branches of the ER UPR, as shown by the upregulation of ATF4 and XBP1s, respectively, and ER stress was found to be an early event. The PERK and IRE1 $\alpha$ UPR branches were the particular focus of this study, given their crucial role in triggering inflammatory responses during ER stress. Under stressful conditions, components of the PERK and IRE1 $\alpha$ UPR arms interact with inflammatory signaling cascades, which results in the upregulation of inflammatory genes and subsequent induction of inflammatory responses. Activated IRE1 interacts with IKK and JNK, leading to activation of the inflammatory mediators NF- $\mathrm{B}$ and AP-1. When activated by phosphorylation, eIF2 $\alpha$, which is a signaling mediator at the PERK UPR branch, is also able to activate NF- $\kappa$ B by inhibiting the translation of I $\mathrm{B} \alpha$ [33].

UPR activation in TG-treated cells was further supported by the tendency of increase in other ER stress markers such as GRP78 and CHOP. These data are in accordance with studies that have emerged over the years reporting consistently the activation of the UPR 
in TG-treated mammalian cells [8,34,35]. ATF4 transcription factor regulates the expression of numerous genes, including the pro-apoptotic factor $\mathrm{CHOP}$. These mediators of the PERK UPR arm play an important role in committing cells to apoptosis under chronic ER stress conditions [35]. Our findings suggest that human monocytes are able to trigger strategies to cope with chronic ER stress upon SERCA inhibition, as indicated by the $17-25 \%$ decrease in viability observed in cells treated with 5 or $10 \mu \mathrm{M}$ TG for $24 \mathrm{~h}$, respectively. Based on ISO 10993-5:2009, "Biological evaluation of medical devices-Part5: Tests for in vitro cytotoxicity", a reduction in cell viability below $30 \%$ is not considered a cytotoxic effect. Therefore, under the present experimental conditions, TG is non-cytotoxic.

Concerning the molecular mechanisms that could be involved in the adaptive response triggered by innate immune cells under stressful conditions, the focus was on Sigma-1Rmediated stress response. Structurally, Sigma-1R is an ER membrane protein that contains an $N$-terminus that faces the cytosol and a C-terminus that faces the ER lumen [36]. Its major action site is the ER, where it can bind specific signaling molecules, such as the ER chaperone GRP78/BiP [16,17,37]. Functionally, in its dormant state, Sigma-1R forms a complex with GRP78/BiP. Under ER stress conditions, Sigma-1R dissociates from GRP78 and regulates the chaperone activity at the ER by stabilizing the IRE1 and $\mathrm{IP}_{3} \mathrm{Rs}[16,38,39]$. Mori and colleagues showed that Sigma-1R is able to associate with activated IRE1, which upregulates ER chaperones [38,39]. Regarding its action on $\mathrm{IP}_{3} \mathrm{Rs}$, Hayashi and $\mathrm{Su}$ found that Sigma-1R$\mathrm{IP}_{3} \mathrm{R}$ complexes prolong ER-to-mitochondria $\mathrm{Ca}^{2+}$ flux under chronic ER stress conditions. Moreover, it was observed that ER stress induced either by TG or tunicamycin, specific ER stressors, promotes the transient expression of Sigma-1R, which was not detected after $3 \mathrm{~h}$. According to these authors, the Sigma-1R upregulation represents a cellular response to stress, and its inhibition $3 \mathrm{~h}$ upon ER stress induction can be explained by a decline in the stability of Sigma-1R protein and/or mRNA [16]. Our data suggest that SERCA inhibition does not activate Sigma-1R-mediated stress response in THP-1 monocytes.

TG is a specific blocker of the SERCA pump, which is crucial for reallocate released $\mathrm{Ca}^{2+}$ back into the ER and maintain $\mathrm{Ca}^{2+}$ homeostasis. Since $\mathrm{Ca}^{2+}$ can activate physiological and pathological signaling pathways, a tight regulation of intracellular $\mathrm{Ca}^{2+}$ concentrations is crucial to maintain proper $\mathrm{Ca}^{2+}$ dynamics and thus preserve normal cell function [4,5]. Due to its mechanism of action, TG administration has been intimately associated with a rapid depletion of ER $\mathrm{Ca}^{2+}$ stores and, subsequently, with an increase in intracellular $\mathrm{Ca}^{2+}$ levels $[2,8]$. Our findings showing enhanced levels of the fusion protein Mfn2 in TG-treated THP-1 cells, together with TEM representative images that show an increase in fused mitochondria in these cells, suggest that mitochondria fusion might be an adaptive response triggered by human monocytes to cope with stress induced by SERCA inhibition. The imbalance of mitochondrial dynamics towards mitochondrial fusion can be responsible for enhanced mitochondrial $\mathrm{Ca}^{2+}$ uptake observed in TG-treated THP-1 cells, which is required to activate enzymes involved in the TCA cycle and ATP production $[40,41]$. This hypothesis is supported by a recent study developed by Lebeau and collaborators that shows that TG-induced ER stress remodels mitochondrial morphology to prevent mitochondrial fragmentation and thus promote mitochondrial metabolism in response to ER stress. Moreover, it was demonstrated that the mechanism that protects mitochondria during ER stress is orchestrated through the PERK branch of the ER UPR. Upon activation, PERK selectively activates eIF $2 \alpha$ by phosphorylation, which, in turn, promotes protective stress-induced mitochondrial hyperfusion [27]. This protective mechanism promotes elongation of mitochondria and avoids fragmentation that triggers mitophagy, and it was previously described as a cellular response to other types of stress, such as starvation, ribosome inhibition, and UV irradiation [42-44]. According to Sabouny et al., mitochondria hyperfusion mediated by the Keap1-Nrf2 pathway in response to stress involves the degradation of the mitochondrial fission protein DRP1 [44]. The enhanced mitochondrial fusion as a protective response to ER stress was further strengthened by data showing that mitochondrial morphology regulates mitochondrial $\mathrm{Ca}^{2+}$ uptake in order to preserve intracellular $\mathrm{Ca}^{2+}$ homeostasis [45]. These authors observed that the increment in mitochondrial 
fusion, which was achieved through the expression of an abnormal form of the fission protein DRP1, increases both mitochondrial $\mathrm{Ca}^{2+}$ uptake and $\mathrm{Ca}^{2+}$ retention capacity in C2C12 cells. Interestingly, they also reported a significant reduction in $\mathrm{Ca}^{2+}$ uptake and retention within mitochondria in cells expressing a fission phenotype that was induced by knockdown of the gene encoding the fusion protein Mfn2 [45]. Additionally, we observed that modulation of mitochondrial dynamics towards increased fusion is independent of alterations in mitochondrial membrane potential. This finding is also corroborated by Kowaltowski and coworkers, showing that the increase in mitochondria fusion in cells expressing abnormal DRP1 is independent of mitochondrial depolarization [45]. The preservation of mitochondrial membrane potential after TG treatment in THP-1 monocytes could be explained by the activity of $\mathrm{Ca}^{2+}$ extrusion systems that avoid mitochondrial $\mathrm{Ca}^{2+}$ overload [46].

ER stress affects mitochondrial function, and, depending on the level of stress, mitochondrial dysfunction can be promoted. Under chronic/severe ER stress, the extensive mitochondria $\mathrm{Ca}^{2+}$ influx is followed by mitochondrial fragmentation, increased ROS production, and loss of membrane potential, which can act as a signal to programmed cell death [47]. Together, the findings herein presented, showing absence of increased mitochondrial fission, membrane depolarization, or accumulation of ROS, indicate that SERCA inhibition in human monocytes does not promote mitochondrial damage, supporting that these innate immune cells are able to cope with stress. Furthermore, the above-mentioned mitochondrial alterations have been implicated in NLRP3-mediated inflammation [23]. Accumulation of mitochondrial ROS and disrupted mitochondrial membrane potential are classical activators of the NLRP3 inflammasome [20-23]. Although the role of mitochondrial dynamics in NLRP3 inflammasome activation is less explored, it has been proposed that fission of the mitochondrial network also plays a role [29]; however, the mechanisms involved are still controversial. On the one hand, Li and coworkers found that inhibition of DRP1-mediated mitochondrial fission blocks NOX2 oxidase signaling, preventing NLRP3 inflammasome activation in palmitate-treated endothelial cells [48]. NOX2 is a NADPH oxidase responsible for the production of ROS in many cells [49]. On the other hand, Park and colleagues demonstrated that activation of the NLRP3 inflammasome in response to LPS plus ATP is regulated by DRP1 in mouse bone marrow-derived macrophages. By silencing DRP1, these authors provided evidence that defective mitochondrial fission activates the NLRP3-dependent caspase- 1 and subsequent IL-1 $\beta$ secretion [29]. Although there were no changes in relevant mitochondrial triggers of NLRP3 inflammasome activation upon SERCA inhibition in THP-1 human monocytes, secreted IL- $1 \beta$ levels were measured as a readout of NLRP3 inflammasome activation by TG-treated THP-1 cells. Under these conditions, extracellular IL- $1 \beta$ secretion was not promoted, and therefore, it can be concluded that NLRP3 inflammasome is not activated upon SERCA inhibition in THP-1 human monocytes. These findings obtained in THP-1 monocytes are supported by a previous study showing that IL- $1 \beta$ secretion in response to TG treatment is not detected in PMA-differentiated THP-1 macrophages [19]. Accordingly, the impact of SERCA inhibition on NLRP3 inflammasome was also evaluated in primary monocytes isolated from peripheral blood of healthy subjects exposed to TG, in the presence or absence of LPS priming. In both cases, extracellular IL-1 $\beta$ levels were not increased, supporting the view that absence of NLRP3 inflammasome activation is a specific early stress response of human monocytes triggered upon SERCA inhibition. Menu and co-workers have demonstrated that TG induces NLRP3 activation in murine LPS-primed bone marrow-derived macrophages [19]. Although both monocytes and macrophages are key components of the innate immune system, the differential response to stress induced by SERCA inhibition suggests that NLRP3 activation in the immune system occurs in a cell type-specific manner. The difference in the response between macrophages and monocytes may be explained by its functions on the innate immune system. As described in the literature, macrophages are the main innate immune cells involved in acute inflammatory responses, which are not so exacerbated in their precursors, the monocytes [50]. 


\section{Conclusions}

This work provides novel evidence that NLRP3 inflammasome is not activated by SERCA inhibition in human monocytes, either in primary monocytes or in the THP-1 monocytic cell line. Our findings from THP-1 cells showing increased mitochondrial fusion under these stressful conditions suggest that human monocytes trigger adaptive strategies through remodeling of mitochondrial morphology towards fusion in order to preserve metabolism and energy production. This mechanism, called mitochondrial hyperfusion, prevents mitochondrial dysfunction in response to ER stress caused by SERCA inhibition, namely ROS accumulation, membrane depolarization, and fission, thus avoiding NLRP3 inflammasome activation and, subsequently, the release of the pro-inflammatory cytokine IL-1 $\beta$. Therefore, human monocytes can counteract early ER stress due to SERCA inhibition by modulating mitochondrial morphology and function in order to preserve energy production and cell survival and to prevent sterile inflammation induced by NLRP3 inflammasome activation.

Author Contributions: The presented experimental work carried out in THP-1 human monocytes and primary human monocytes was performed by A.C.P.; N.M., S.M. and A.M. were fundamental in the selection of the cohort of healthy volunteers included in this study. M.T.C. and C.M.F.P. designed the study, supervised the experiments, and were also involved in the preparation of the manuscript. All authors have read and agreed to the published version of the manuscript.

Funding: This work was funded by the European Regional Development Fund (ERDF), through the Centro 2020 Regional Operational Programme under project CENTRO-01-0145-FEDER-000012 (HealthyAging2020) and through the COMPETE 2020-Operational Programme for Competitiveness and Internationalisation and Portuguese national funds via FCT—Fundação para a Ciência e a Tecnologia, under projects POCI-01-0145-FEDER-028214 (MAM4BD) and POCI-01-0145-FEDER029369 and UIDB/04539/2020 and UIDP/04539/2020. Ana Catarina Pereira is recipient of PhD fellowship from FCT (SFRH/BD/148653/2019).

Institutional Review Board Statement: The study was conducted according to the guidelines of the Declaration of Portugal and approved by the local ethics committee from Hospitals from University of Coimbra (CHUC), Portugal (150/CES, 3 July).

Informed Consent Statement: Informed consent was obtained from all subjects involved in the study.

Data Availability Statement: The datasets used and/or analyzed during the current study are available from the corresponding author on reasonable request.

Acknowledgments: The authors thank Mónica Zuzarte for the services provided in the field of transmission electron microscopy.

Conflicts of Interest: The authors declare no conflict of interest.

\section{References}

1. Lai, E.; Teodoro, T.; Volchuk, A. Endoplasmic Reticulum Stress: Signaling the Unfolded Protein Response. Physiology 2007, 22, 193-201. [CrossRef]

2. Tadini-Buoninsegni, F.; Smeazzetto, S.; Gualdani, R.; Moncelli, M.R. Drug Interactions With the $\mathrm{Ca}^{2+}$-ATPase From Sarco(Endo)Plasmic Reticulum (SERCA). Front. Mol. Biosci. 2018, 5, 36. [CrossRef] [PubMed]

3. Aguayo-Ortiz, R.; Espinoza-Fonseca, L.M. Linking Biochemical and Structural States of SERCA: Achievements, Challenges, and New Opportunities. Int. J. Mol. Sci. 2020, 21, 4146. [CrossRef]

4. Bagur, R.; Hajnóczky, G. Intracellular $\mathrm{Ca}^{2+}$ Sensing: Its Role in Calcium Homeostasis and Signaling. Mol. Cell 2017, 66, 780-788. [CrossRef] [PubMed]

5. Chemaly, E.R.; Troncone, L.; Lebeche, D. SERCA control of cell death and survival. Cell Calcium 2018, 69, 46-61. [CrossRef] [PubMed]

6. Jaskulska, A.; Janecka, A.E.; Gach-Janczak, K. Thapsigargin—From Traditional Medicine to Anticancer Drug. Int. J. Mol. Sci. 2020, 22, 4. [CrossRef]

7. Oslowski, C.M.; Urano, F. Measuring ER Stress and the Unfolded Protein Response Using Mammalian Tissue Culture System. In Methods in Enzymology; Elsevier BV: Amsterdam, The Netherlands, 2011; Volume 490, pp. 71-92. 
8. Sehgal, P.; Szalai, P.; Olesen, C.; Praetorius, H.A.; Nissen, P.; Christensen, S.B.; Engedal, N.; Møller, J.V. Inhibition of the sarco/endoplasmic reticulum (ER) $\mathrm{Ca}^{2+}$-ATPase by thapsigargin analogs induces cell death via ER Ca2+ depletion and the unfolded protein response. J. Biol. Chem. 2017, 292, 19656-19673. [CrossRef]

9. Hetz, C.; Chevet, E.; Oakes, S.A. Proteostasis control by the unfolded protein response. Nat. Cell Biol. 2015, 17, 829-838. [CrossRef]

10. Karagoz, G.E.; Acosta-Alvear, D.; Walter, P. The Unfolded Protein Response: Detecting and Responding to Fluctuations in the Protein-Folding Capacity of the Endoplasmic Reticulum. Cold Spring Harb. Perspect. Biol. 2019, 11, 033886. [CrossRef]

11. Wang, M.; Wey, S.; Zhang, Y.; Ye, R.; Lee, A.S. Role of the Unfolded Protein Response Regulator GRP78/BiP in Development, Cancer, and Neurological Disorders. Antioxid. Redox Signal. 2009, 11, 2307-2316. [CrossRef]

12. Hetz, C.; Papa, F.R. The Unfolded Protein Response and Cell Fate Control. Mol. Cell 2018, 69, 169-181. [CrossRef] [PubMed]

13. Iurlaro, R.; Muñoz-Pinedo, C. Cell death induced by endoplasmic reticulum stress. FEBS J. 2016, 283, 2640-2652. [CrossRef] [PubMed]

14. Hayashi, T. The Sigma-1 Receptor in Cellular Stress Signaling. Front. Neurosci. 2019, 13, 733. [CrossRef] [PubMed]

15. Su, T.-P.; Hayashi, T.; Maurice, T.; Buch, S.; Ruoho, A.E. The sigma-1 receptor chaperone as an inter-organelle signaling modulator. Trends Pharmacol. Sci. 2010, 31, 557-566. [CrossRef]

16. Hayashi, T.; Su, T.-P. Sigma-1 Receptor Chaperones at the ER- Mitochondrion Interface Regulate Ca ${ }_{2+}$ Signaling and Cell Survival Cell 2007, 131, 596-610. [CrossRef] [PubMed]

17. Ortega-Roldan, J.L.; Ossa, F.; Schnell, J.R. Characterization of the Human Sigma-1 Receptor Chaperone Domain Structure and Binding Immunoglobulin Protein (BiP) Interactions. J. Biol. Chem. 2013, 288, 21448-21457. [CrossRef]

18. Hotamisligil, G.S. Endoplasmic Reticulum Stress and the Inflammatory Basis of Metabolic Disease. Cell 2010, 140, 900-917. [CrossRef]

19. Menu, P.; Mayor, A.; Zhou, R.; Tardivel, A.; Ichijo, H.; Mori, K.; Tschopp, J. ER stress activates the NLRP3 inflammasome via an UPR-independent pathway. Cell Death Dis. 2012, 3, e261. [CrossRef]

20. Guo, H.; Callaway, J.B.; Ting, J.P.-Y. Inflammasomes: Mechanism of action, role in disease, and therapeutics. Nat. Med. 2015, 21, 677-687. [CrossRef]

21. He, Y.; Hara, H.; Núñez, G. Mechanism and Regulation of NLRP3 Inflammasome Activation. Trends Biochem. Sci. 2016, 41, 1012-1021. [CrossRef]

22. Walsh, J.G.; Muruve, D.A.; Power, C. Inflammasomes in the CNS. Nat. Rev. Neurosci. 2014, 15, 84-97. [CrossRef] [PubMed]

23. Holley, C.L.; Schroder, K. The rOX-stars of inflammation: Links between the inflammasome and mitochondrial meltdown. Clin. Transl. Immunol. 2020, 9, e01109. [CrossRef] [PubMed]

24. Liu, Y.J.; McIntyre, R.; Janssens, G.E.; Houtkooper, R.H. Mitochondrial fission and fusion: A dynamic role in aging and potential target for age-related disease. Mech. Ageing Dev. 2020, 186, 111212. [CrossRef] [PubMed]

25. Filadi, R.; Pendin, D.; Pizzo, P. Mitofusin 2: From functions to disease. Cell Death Dis. 2018, 9, 1-13. [CrossRef]

26. Twig, G.; Shirihai, O.S. The Interplay Between Mitochondrial Dynamics and Mitophagy. Antioxid. Redox Signal. 2011, 14, 1939-1951. [CrossRef]

27. Lebeau, J.; Saunders, J.M.; Moraes, V.W.; Madhavan, A.; Madrazo, N.; Anthony, M.C.; Wiseman, R.L. The PERK Arm of the Unfolded Protein Response Regulates Mitochondrial Morphology during Acute Endoplasmic Reticulum Stress. Cell Rep. 2018, 22, 2827-2836. [CrossRef]

28. Kowald, A.; Kirkwood, T.B.L. Evolution of the mitochondrial fusion-fission cycle and its role in aging. Proc. Natl. Acad. Sci. USA 2011, 108, 10237-10242. [CrossRef]

29. Park, S.; Won, J.-H.; Hwang, I.; Hong, S.; Lee, H.K.; Yu, J.-W. Defective mitochondrial fission augments NLRP3 inflammasome activation. Sci. Rep. 2015, 5, 15489. [CrossRef]

30. Gao, F.; Reynolds, M.B.; Passalacqua, K.D.; Sexton, J.Z.; Abuaita, B.H.; O’Riordan, M.X.D. The Mitochondrial Fission Regulator DRP1 Controls Post-Transcriptional Regulation of TNF- $\alpha$. Front. Cell. Infect. Microbiol. 2021, 10, 1-14. [CrossRef]

31. Yang, Y.; Wang, H.; Kouadir, M.; Song, H.; Shi, F. Recent advances in the mechanisms of NLRP3 inflammasome activation and its inhibitors. Cell Death Dis. 2019, 10,1-11. [CrossRef]

32. Wang, Z.; Zhang, S.; Xiao, Y.; Zhang, W.; Wu, S.; Qin, T.; Yue, Y.; Qian, W.; Li, L. NLRP3 Inflammasome and Inflammatory Diseases. Oxidative Med. Cell. Longev. 2020, 2020, 4063562-11. [CrossRef] [PubMed]

33. So, J.-S. Roles of Endoplasmic Reticulum Stress in Immune Responses. Mol. Cells 2018, 41, 705-716. [CrossRef] [PubMed]

34. Chen, L.H.; Jiang, C.C.; Avery-Kiejda, K.; Wang, Y.F.; Thorne, R.F.; Zhang, X.D.; Hersey, P. Thapsigargin sensitizes human melanoma cells to TRAIL-induced apoptosis by up-regulation of TRAIL-R2 through the unfolded protein response. Carcinogenesis 2007, 28, 2328-2336. [CrossRef] [PubMed]

35. Lindner, P.; Christensen, S.B.; Nissen, P.; Møller, J.V.; Engedal, N. Cell death induced by the ER stressor thapsigargin involves death receptor 5, a non-autophagic function of MAP1LC3B, and distinct contributions from unfolded protein response components. Cell Commun. Signal. 2020, 18, 1-23. [CrossRef] [PubMed]

36. Schmidt, H.; Zheng, S.; Gurpinar, E.; Koehl, A.; Manglik, A.K.A.; Kruse, A.C. Crystal structure of the human $\sigma 1$ receptor. Nature 2016, 532, 527-530. [CrossRef]

37. Yano, H.; Bonifazi, A.; Xu, M.; Guthrie, D.A.; Schneck, S.N.; Abramyan, A.M.; Fant, A.D.; Hong, W.C.; Newman, A.H.; Shi, L. Pharmacological profiling of sigma 1 receptor ligands by novel receptor homomer assays. Neuropharmacology 2018, 133, 264-275. [CrossRef] [PubMed] 
38. Mori, K. The unfolded protein response: The dawn of a new field. Proc. Jpn. Acad. Ser. B 2015, 91, 469-480. [CrossRef]

39. Mori, T.; Hayashi, T.; Hayashi, E.; Su, T.-P. Sigma-1 Receptor Chaperone at the ER-Mitochondrion Interface Mediates the Mitochondrion-ER-Nucleus Signaling for Cellular Survival. PLoS ONE 2013, 8, e76941. [CrossRef]

40. Hayashi, T.; Rizzuto, R.; Hajnoczky, G.; Su, T.-P. MAM: More than just a housekeeper. Trends Cell Biol. 2009, 19, 81-88. [CrossRef]

41. Ainbinder, A.; Boncompagni, S.; Protasi, F.; Dirksen, R.T. Role of Mitofusin-2 in mitochondrial localization and calcium uptake in skeletal muscle. Cell Calcium 2015, 57, 14-24. [CrossRef]

42. Tondera, D.; Grandemange, S.; Jourdain, A.; Karbowski, M.; Mattenberger, Y.; Herzig, S.; Da Cruz, S.; Clerc, P.; Raschke, I.; Merkwirth, C.; et al. SLP-2 is required for stress-induced mitochondrial hyperfusion. EMBO J. 2009, 28, 1589-1600. [CrossRef] [PubMed]

43. Gomes, L.C.; Di Benedetto, G.; Scorrano, L. During autophagy mitochondria elongate, are spared from degradation and sustain cell viability. Nat. Cell Biol. 2011, 13, 589-598. [CrossRef] [PubMed]

44. Sabouny, R.; Fraunberger, E.; Geoffrion, M.; Ng, A.C.-H.; Baird, S.D.; Screaton, R.A.; Milne, R.; McBride, H.; Shutt, T. The Keap1-Nrf2 Stress Response Pathway Promotes Mitochondrial Hyperfusion Through Degradation of the Mitochondrial Fission Protein Drp1. Antioxid. Redox Signal. 2017, 27, 1447-1459. [CrossRef] [PubMed]

45. Kowaltowski, A.J.; Menezes-Filho, S.L.; Assali, E.A.; Gonçalves, I.G.; Cabral-Costa, J.V.; Abreu, P.; Miller, N.; Nolasco, P.; Laurindo, F.R.M.; Bruni-Cardoso, A.; et al. Mitochondrial morphology regulates organellar Ca2+uptake and changes cellular Ca2+homeostasis. FASEB J. 2019, 33, 13176-13188. [CrossRef] [PubMed]

46. Romero-Garcia, S.; Prado-Garcia, H. Mitochondrial calcium: Transport and modulation of cellular processes in homeostasis and cancer (Review). Int. J. Oncol. 2019, 54, 1155-1167. [CrossRef]

47. Rainbolt, T.; Saunders, J.M.; Wiseman, R.L. Stress-responsive regulation of mitochondria through the ER unfolded protein response. Trends Endocrinol. Metab. 2014, 25, 528-537. [CrossRef] [PubMed]

48. Li, Y.; Zhou, Z.-H.; Chen, M.-H.; Yang, J.; Leng, J.; Cao, G.-S.; Xin, G.-Z.; Liu, L.-F.; Kou, J.-P.; Liu, B.-L.; et al. Inhibition of Mitochondrial Fission and NOX2 Expression Prevent NLRP3 Inflammasome Activation in the Endothelium: The Role of Corosolic Acid Action in the Amelioration of Endothelial Dysfunction. Antioxid. Redox Signal. 2016, 24, 893-908. [CrossRef] [PubMed]

49. Panday, A.; Sahoo, M.; Osorio, D.; Batra, S. NADPH oxidases: An overview from structure to innate immunity-associated pathologies. Cell. Mol. Immunol. 2015, 12, 5-23. [CrossRef]

50. Kumar, V. Macrophages: The Potent Immunoregulatory Innate Immune Cells. In Macrophage Activation-Biology and Disease; IntechOpen: London, UK, 2020. [CrossRef] 